\title{
Shock tube study of kerosene ignition delay at high pressures
}

\author{
LIANG JinHu ${ }^{1,2}$, WANG $\mathrm{Su}^{2 *}$, HU HongHao ${ }^{1,2}$, ZHANG ShengTao ${ }^{1}$, \\ FAN BingCheng ${ }^{2} \&$ CUI JiPing ${ }^{2}$ \\ ${ }^{1}$ College of Chemistry and Chemical Engineering, Chongqing University, Chongqing 400044, China; \\ ${ }^{2}$ State Key Laboratory of High Temperature Gas Dynamics, Institute of Mechanics, Chinese Academy of Sciences, Beijing 100190, China
}

Received December 31, 2011; accepted March 14, 2012; published online April 18, 2012

\begin{abstract}
Ignition delay times of China No. 3 aviation kerosene were measured behind reflected shock waves using a heated high-pressure shock tube. Experimental conditions covered a wider temperature range of 820-1500 K, at pressures of 5.5, 11 and $22 \mathrm{~atm}$, equivalence ratios of $0.5,1.0$ and 1.5, and oxygen concentration of 20\%. Adsorption of kerosene on the shock tube wall was taken into account. Ignition delay times were determined from the onset of the excited radical $\mathrm{OH}$ emission in conjunction with the pressure profiles. The experimental results of ignition delay time were correlated with the equations: $\tau=3.2 \times 10^{-11}[\text { Kerosene }]^{0.22}\left[\mathrm{O}_{2}\right]^{-1.09} \exp (69941 / R T)$ and $\tau=4.72 \times 10^{-7} P^{-0.88} \phi^{0.23} \exp (62092 / R T)$. The current measurements provide the ignition delay behavior of China No. 3 aviation kerosene at high pressures and air-like $\mathrm{O}_{2}$ concentration.
\end{abstract}

ignition delay time, kerosene, shock tube, high pressure

PACS number(s): 82.40.Fp, 82.33.Vx, 89.30.A-, 07.35+k

Citation: $\quad$ Liang J H, Wang S, Hu H H, et al. Shock tube study of kerosene ignition delay at high pressures. Sci China-Phys Mech Astron, 2012, 55: 947-954, doi: $10.1007 / \mathrm{s} 11433-012-4723-8$

The ignition delay time of fuel is usually considered as a characteristic time to scale the duration of gas flow passing through a combustion chamber, which is a criterion to measure the capability of ignition in the engine [1-3]. When using computational fluid dynamics (CFD) to simulate the real process in a combustion chamber, a simplified chemical reaction model is necessary. The development and refinement of reaction models for combustion processes requires an extensive database of kinetic targets. Shock tube experiments can provide data for this purpose, including reaction rate constants, species time histories, and ignition delay times. Ignition delay times, in particular, provide the simplest overall performance characteristics of a combustion system [4]. One of the criteria of reaction model validation is that it should correctly reflect the behavior of ignition delay time.

*Corresponding author (email: suwang@imech.ac.cn)
Kerosene is an important hydrocarbon fuel preferred for scramjets and pulsed detonation engines (PDE) because of its stable thermodynamic properties and high energy density. Although measurements of ignition delay time of hydrocarbons have been the focus of many investigations over the past years, only a few data exist for kerosene. Some earlier studies on the ignition delay of kerosene utilized continuous flow apparatus. The representative work by Mullins [5] has been used to characterize the ignition behaviors of kerosene. However, this data was obtained in a combustion rig fed with hot vitiated air. In recent years, some studies on kerosene ignition delay have been conducted in shock tubes. Dean et al. [6] investigated the ignition delay of Jet-A in air at the pressure of $8 \mathrm{~atm}$, within a temperature range of 1000-1800 K. Vasu et al. [7] carried out the experiments on ignition delay times for Jet-A at pressures of 17-51 atm, temperatures of 715-1229 $\mathrm{K}$ and oxygen concentrations of $10 \%$ and $21 \%$. Steil et al. [8] measured Jet-A ignition times 
in highly diluted mixtures with 900 ppm Jet-A, within a temperature range of $1250-1700 \mathrm{~K}$ and at pressures of 2.9-5.9 atm. Kumar and Sung [9] measured ignition delay times of Jet-A using a heated rapid compression machine at pressures of 7-30 atm and within the lower temperature range from $650-1100 \mathrm{~K}$. Wang et al. [10] measured ignition delay times of gaseous kerosene with higher dilutions of 98-93\% Ar at varied pressures of 1.6-5.0 atm. Liao et al. [11] measured kerosene ignition delay times at pressures of 1-6 atm in an aerosol shock tube to study heterogeneous ignition. The test fuel used by most investigators is Jet-A, only Wang et al. [10] and Liao et al. [11] used China No. 3 aviation kerosene in experiments. However, it is not known if differences in chemical composition between Jet- $\mathrm{A}$ and China No. 3 aviation kerosene also alter the ignition and combustion characteristics. Furthermore, some experimental studies and kinetic modeling computations show that ignition delay times under high pressure conditions with low dilution level are considerably different from those under lower pressure and high dilution conditions [12-14].

In order to better match the conditions near to those of practical combustion devices, it is often necessary to conduct ignition delay measurements in less diluted mixtures and at higher pressures. Thus, the aim of the present work is to give more insight into the ignition behavior of China No. 3 aviation kerosene at higher pressures, in highly concentrated fuel mixtures and over a wider temperature range, particularly extending lower temperatures, below $1000 \mathrm{~K}$.

\section{Experimental}

Kerosene is a complex mixture of several hundreds of hydrocarbons including alkanes, cycloalkanes, aromatics and polycyclic compounds, and the detailed composition of kerosene generally varies with each source. In this work, the test fuel is China No. 3 aviation kerosene, including approximately $92.5 \%$ saturated hydrocarbons, $0.5 \%$ unsaturated hydrocarbons, and 7\% aromatic compounds [15].

Shock tubes are a common choice to measure ignition delay times because of its almost instantaneous heating of the reactant mixture by shock wave, the near adiabatic con- stant-volume behavior of shock tube reflected-shock environment, and the ability of shock tubes to access a wide range of conditions of interest for practical combustion devices.

All experiments were carried out in a high-pressure, stainless steel shock tube at the Institute of Mechanics, Chinese Academy of Sciences. The length of the driver section is $6.0 \mathrm{~m}$, and that of the driven section $4.1 \mathrm{~m}$. Both have circular cross sections with an inner diameter of 100 $\mathrm{mm}$. The driver and driven sections are separated by a $0.2 \mathrm{~m}$ long double-diaphragm chamber, which is intended for bursting the two diaphragms at a preassigned pressure. Scored aluminum diaphragms were used in all experiments. Helium and nitrogen were used as the driver gas. The proportions and pressures of two driver gases and the initial pressures of the test mixtures were varied in order to obtain different experimental temperatures and pressures. For most of the present experiments, test observation times were kept in the range of 4-6 ms. However, for experiments with observed ignition delay times greater than $5 \mathrm{~ms}$, tailored helium/nitrogen driver gas mixtures were used. The tailored driver gas mixtures allowed test observation times to be extended up to $15 \mathrm{~ms}$.

The driven section was evacuated down to the ultimate pressure of $3 \times 10^{-7}$ atm by a turbo-molecular pump before filled with test gas. The gas leak rate was less than $1 \times 10^{-6}$ $\mathrm{atm} / \mathrm{min}$. Incident shock velocities were determined by using three piezoelectric pressure transducers (PZT) mounted on the shock tube sidewall equally spaced at $0.5 \mathrm{~m}$ intervals. The last transducer mounted on the endwall of the driven section was used to give the exact time of arrival of the shock at the endwall, and to monitor the pressure evolution in the reflected shock regime. A quartz window was installed on the sidewall very close to the endwall of the driven section for monitoring emission signals from the ignition process in the reflected shock region. Emission signals focused through a lens were detected by using a photomultiplier after passing through a monochromator centered at the emission line of $\mathrm{OH}^{*}(306.5 \mathrm{~nm})$. Pressure and emission signals were recorded finally by a transient A/D transducer. A schematic diagram of the shock tube facility is shown in Figure 1.

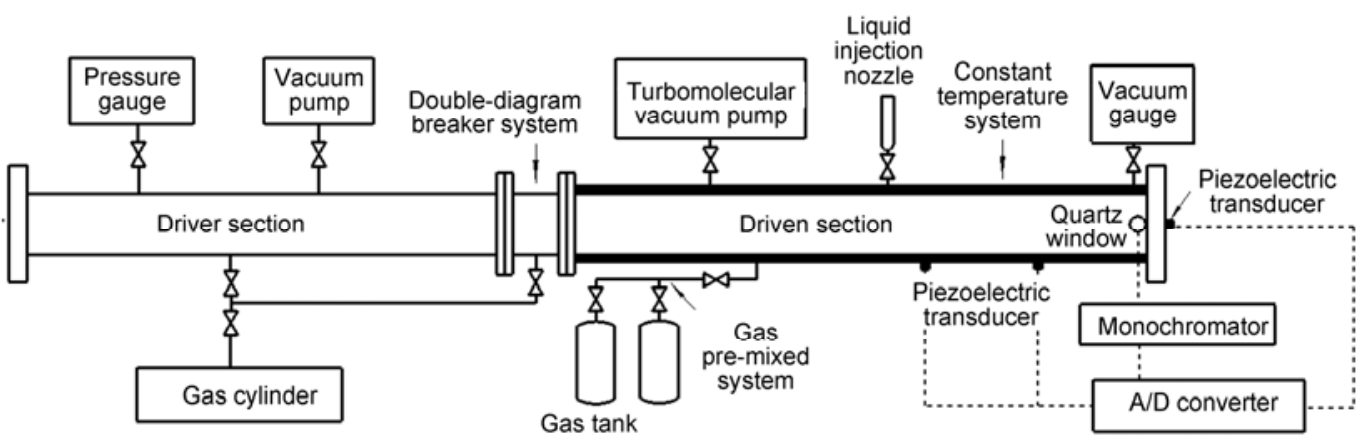

Figure 1 Schematic diagram of the shock tube. 
Kerosene is a complex mixture of many heavy hydrocarbon components. The vapor saturation pressures of heavy hydrocarbons are low at room temperature. There exists a strong adsorption of kerosene on the shock tube wall in experiments, resulting in an uncertainty in the composition determination of the test gas mixtures. An adsorption measurement by gas chromatography showed that the adsorption content of different components of kerosene varies, leading to the gas composition different from the liquid composition [10]. The low vapor pressure of kerosene also limits the experimental concentration range. To minimize the adsorption degree and to increase test vapor pressures of kerosene, the driven section of the shock tube was heated and maintained at a temperature of $135^{\circ} \mathrm{C}$ throughout each experiment. The heating system was controlled by nine thermocouples placed along the driven section of the shock tube. Every thermocouple had an independent electrical circuit to provide a uniform temperature for the setup.

To estimate the adsorption degree of kerosene on the shock tube wall, the adsorption curves of China No. 3 aviation kerosene in the driven section maintained at $135^{\circ} \mathrm{C}$ were measured using a high-precision vacuum gauge for 7 min after injecting the liquid kerosene. A membrane vacuum gauge (Beijing Vacuum Instrument Factory, Model ZDM-1) was selected to measure kerosene pressures, with a resolution of $1 \times 10^{-6}$ atm at the working pressure under $1 \times 10^{-2}$ atm and $1 \times 10^{-3}$ atm at the working pressure above $1 \times 10^{-2} \mathrm{~atm}$. The adsorption curves in Figure 2 show that the adsorption equilibriums are achieved completely in $6 \mathrm{~min}$. Thus pressures were measured 6 min after injecting kerosene as initial experimental pressures.

With respect to the strong propensity of kerosene adsorption on the shock tube wall, experiments were not carried out as usual with a premixed mixture of fuel, oxygen and diluent gas. The mixtures of $\mathrm{O}_{2}(99.995 \%$ pure $)$ and diluent $\operatorname{Ar}(99.99 \%$ pure) were prepared manometrically in a stainless steel tank of 24 liters, and after preparation, the mixtures were left for more than 12 hours to mix and homogenize before use. After the driven section of the shock tube was evacuated to the ultimate pressure in each run, a small amount of kerosene was injected into it, and the pressure was measured 6 min after the fuel evaporated and adsorbed. Then, the prepared mixture of $\mathrm{O}_{2}$ and Ar was added into the driven section, and an additional 10 min was allowed for the gases to fully mix. To ascertain that $10 \mathrm{~min}$ was sufficient for mixing the gases fully, two sets of comparative experiments were conducted with the mixing time of 10 and 20 min, respectively. Figure 3 shows a good agreement between these two sets of experiments with different mixing times. This helps to provide some confidence in taking the mixing time of $10 \mathrm{~min}$ in this study.

Gaseq code [16] was used for computation of the reflected shock conditions by assuming frozen chemistry from measured shock velocities. Because of the complex mixture of several hundreds of hydrocarbons, the detailed composition of kerosene is difficult to determine. In the present study, a three-formula surrogate model [15] consisting of $49 \%$ n-decane, 44\% 1,3,5-trimethylcyclohexane, and 7\% n-propyl-benzene in mole was adopted to represent China No. 3 aviation kerosene, which gives a good simulation for

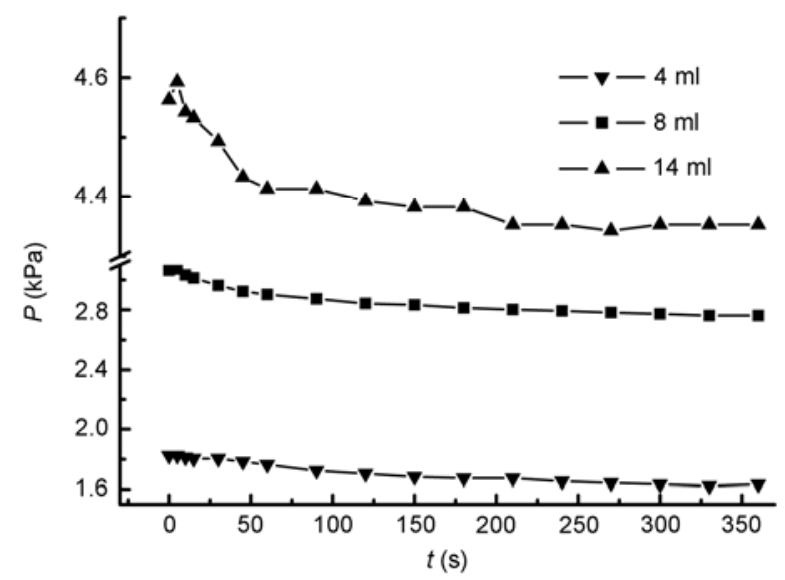

Figure 2 Adsorption curves of China No. 3 aviation kerosene.

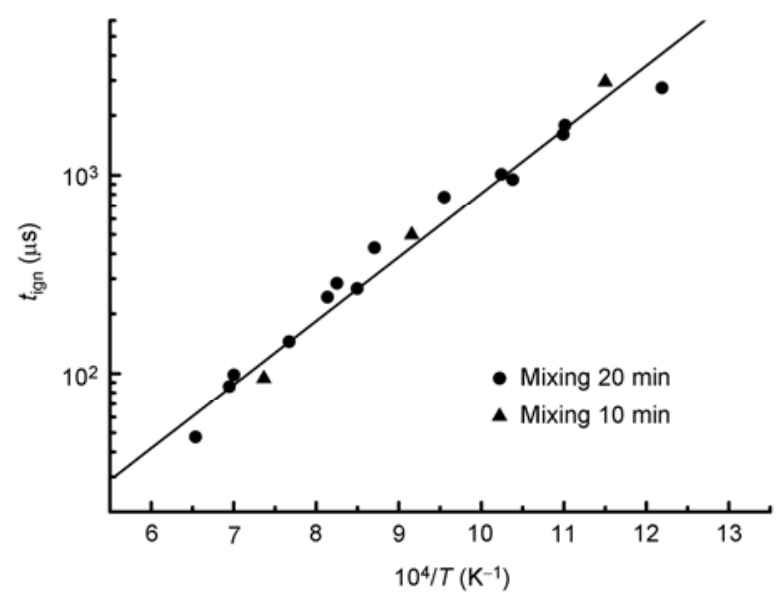

Figure 3 Comparison of ignition delay times with different mixing times.

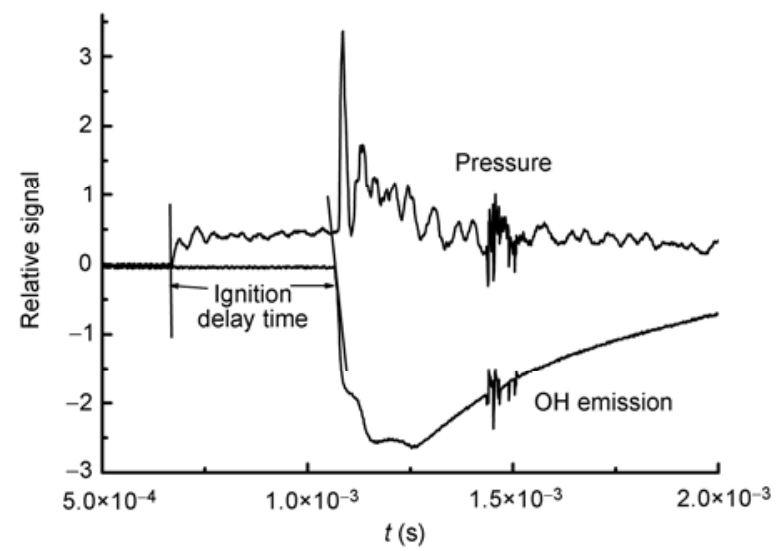

Figure 4 Example measurement of $\mathrm{OH}$ emission and pressure signal for initial reflected shock conditions of $1320 \mathrm{~K}, 5.1 \mathrm{~atm}$, and $\Phi=1.0$. 
the thermophysical and transport properties of China No. 3 aviation kerosene. The averaged formula of China No. 3 aviation deduced from this surrogate model is $\mathrm{C}_{9.49} \mathrm{H}_{19.5}$ for calculations.

The pressures and emissions of $\mathrm{OH}^{*}$ at $306.5 \mathrm{~nm}$ behind reflected shock waves were recorded after bursting of the diaphragms. The $\mathrm{OH}^{*}$ emission signal is a good indicator of ignition. In the present study, the ignition delay time is defined as the time interval between the arrival of the reflected shock wave and the onset of $\mathrm{OH}^{*}$ emission at the sidewall observation location, which is usually determined by linearly extrapolating the steepest slope to the zero signal level of emission. The arrival of the reflected shock wave was determined by the step rise in pressure behind reflected shock waves. Shown in Figure 4 is an example of the pressure and $\mathrm{OH}^{*}$ emission signal traces in the present experiments.

Argon is often used as a diluent gas because its lack of a vibrational mode eliminates the possible influence of vibrational relaxation when calculating postshock conditions. Additionally, it eliminates or minimizes the shock bifurcation on sidewall in the reflected shock regime. Hence, optimized reflected shock conditions are typically obtained using dilute mixtures in argon. However, highly diluted mixtures in argon are not similar in composition to those used in practical combustion devices, where air is typically the oxidizer and the fuel concentration is near $1 \%$ in mol at stoichiometric conditions. Therefore, the present experiments were performed in air-like oxygen concentration of $20 \%$ and at high pressures for practical combustion engine conditions.

The uncertainties in shock tube experiments are mainly associated with nonideality and measurement uncertainty. It is generally agreed that the nonideality is the consequence of both the choice of operating conditions and also the physical construction of the shock tube itself. The degree of nonideality behind reflected shock waves, which is reflected by the measured pressure profiles, is the key factor affecting the accuracy of the conventional treatment using constant temperature and pressure behind reflected shock waves from the one-dimensional shock relations. Tang and Brezinsky [17] have investigated the nonideal behavior in a 5.6 $\mathrm{m}$ long shock tube with an inner diameter of $50.8 \mathrm{~mm}$ and found that the temperature increase due to the pressure variation, $\Delta \mathrm{T}_{5}$, can be up to $55 \mathrm{~K}$ at $25 \mathrm{~atm}$ and $1270 \mathrm{~K}$. They concluded that for shock tube experiments with a less than $15 \%$ endwall pressure increase, the conventional treatment is suitable to study chemical kinetics. A $0.5 \%$ uncertainty in shock wave velocity measurements results in about $1 \%$ and $2 \%$ experimental errors in temperature and pressure behind reflected shock waves. Usually, this can result in a $10 \%-$ $15 \%$ uncertainty in ignition delay times.

\section{Results and discussion}

Ignition delay times were measured for three different Kerosene $/ \mathrm{O}_{2} / \mathrm{Ar}$ mixtures with equivalence ratios of $\phi=0.5,1.0$ and 1.5 , respectively. The initial compositions of the test mixtures are presented in Table 1. The experimental ignition delay time data are summarized in Table 2 . In some experiments at $22 \mathrm{~atm}$, the strong ignition was observed because of the large fuel concentrations employed. As a consequence, a transition to detonation can occur that would make the interpretation of shock tube data even more complicated. Therefore, the experiments at $22 \mathrm{~atm}$ were limited to lean equivalence ratios of $\phi=0.5$ and 1.0.

The effect of pressure on ignition delay times of kerosene is shown in Figures 5-7. The ignition delay times of kerosene are shown to decrease with increasing pressure, and the temperature dependence of kerosene ignition delay times clearly shows a consistent rise with increasing pressure. The ignition activation energy at $\phi=0.5$ increases from 42.0 $\mathrm{kJ} / \mathrm{mol}$ at $5.5 \mathrm{~atm}$ to $67.5 \mathrm{~kJ} / \mathrm{mol}$ at $22 \mathrm{~atm}$. This increase in activation energy with increasing pressure for kerosene ignition is also identical for the stoichiometric ratios of $\phi=1.0$ and 1.5 .

The effect of stoichiometry on ignition delay times of kerosene is shown in Figures 8-10. As seen in these figures, at a given pressure, the ignition delay times of kerosene do not change dramatically with changing equivalence ratio.

For other hydrocarbon fuels, the ignition delay times usually undergo a greater change when changing the equivalence ratio [18]. Such difference may be attributed to the procedure of changing equivalence ratio. There are two procedures to change stoichiometry. That is, the amount of fuel relative to the diluent changes at a fixed oxygen mole fraction and vice versa. When changing stoichiometry at a fixed fuel mole fraction, both oxygen and diluent mole fractions will undergo a dramatic change, and this becomes even more evident for heavy hydrocarbon fuels. Because we are interested in shock tube conditions applicable for practical devices, the experiment results in the present study are presented at the fixed oxygen mole fraction of about $20 \%$. Furthermore, the temperature dependence of kerosene ignition delay times shows a decrease with increasing equivalence ratio, except for $\phi=0.5$ at $5.5 \mathrm{~atm}$. This sensitivity to stoichiometry leads the trend lines of ignition delay times with respective equivalence ratios possibly to intersect with each other over the range of temperatures studied, as shown in Figure 8 and 9. As the pressure increases, the intersection temperature decreases. Figure 10 shows that two trend lines

Table 1 Initial composition of the test mixtures (mole fractions)

\begin{tabular}{ccccc}
\hline No. & $\phi$ & Kerosene & $\mathrm{O}_{2}$ & $\mathrm{Ar}$ \\
\hline 1 & 0.5 & $0.60 \%$ & $19.88 \%$ & $79.52 \%$ \\
2 & 1.0 & $1.20 \%$ & $19.88 \%$ & $78.92 \%$ \\
3 & 1.5 & $1.80 \%$ & $19.88 \%$ & $78.32 \%$ \\
\hline
\end{tabular}


Table 2 Summary of ignition delay experimental results

\begin{tabular}{|c|c|c|c|c|c|}
\hline$T_{5}(\mathrm{~K})$ & $P_{5}(\mathrm{~atm})$ & $t_{\text {ign }}(\mu \mathrm{s})$ & $T_{5}(\mathrm{~K})$ & $P_{5}(\mathrm{~atm})$ & $t_{\mathrm{ign}}(\mu \mathrm{s})$ \\
\hline \multicolumn{6}{|c|}{ Kerosene $/ \mathrm{O}_{2} / \mathrm{Ar}, \phi=0.5$, Kerosene $=0.6 \%, \mathrm{O}_{2}=19.88 \%, \mathrm{Ar}=79.52 \%$} \\
\hline 1325.7 & 5.2 & 269.9 & 934.7 & 10.4 & 764.1 \\
\hline 1116.0 & 5.1 & 734.1 & 939.8 & 13.2 & 756.9 \\
\hline 946.3 & 5.7 & 1540.6 & 901.4 & 12.3 & 3032.8 \\
\hline 1183.2 & 5.2 & 540.0 & 1079.7 & 10.6 & 299.8 \\
\hline 885.5 & 5.5 & 1610.5 & 824.0 & 9.9 & 4197.7 \\
\hline 1363.9 & 5.1 & 236.7 & 1183.7 & 11.2 & 155.6 \\
\hline 915.0 & 5.2 & 1662.1 & 909.0 & 12.2 & 2225.0 \\
\hline 976.7 & 4.9 & 1216.5 & 872.4 & 11.4 & 3346.7 \\
\hline 1050.0 & 5.7 & 1025.3 & 836.9 & 9.7 & 4919.3 \\
\hline 1501.3 & 12.1 & 20.2 & 1209.0 & 22.2 & 54.5 \\
\hline 1353.7 & 12.5 & 46.3 & 1103.5 & 22.8 & 117.9 \\
\hline 1304.7 & 12.4 & 63.8 & 1057.8 & 24.4 & 235.5 \\
\hline 1277.9 & 12.7 & 71.1 & 1017.2 & 25.2 & 350.5 \\
\hline 1173.9 & 12.7 & 172.5 & 957.8 & 24.1 & 495.1 \\
\hline 1101.3 & 11.0 & 514.3 & 897.8 & 23.9 & 912.5 \\
\hline 1040.3 & 10.1 & 377.6 & 1281.8 & 21.7 & 32.2 \\
\hline \multicolumn{6}{|c|}{ Kerosene $/ \mathrm{O}_{2} / \mathrm{Ar}, \phi=1.0$, Kerosene $=1.2 \%, \mathrm{O}_{2}=19.88 \%, \mathrm{Ar}=78.92 \%$} \\
\hline 1121.9 & 5.0 & 922.2 & 1403.9 & 13.4 & 86.0 \\
\hline 913.3 & 5.5 & 2661.0 & 909.6 & 7.9 & 1608.3 \\
\hline 1162.5 & 5.0 & 607.2 & 1041.5 & 10.8 & 775.0 \\
\hline 894.0 & 6.2 & 2958.8 & 1196.7 & 9.5 & 284.9 \\
\hline 979.2 & 5.6 & 1572.8 & 1281.0 & 10.8 & 144.8 \\
\hline 1074 & 5.9 & 1080 & 822.3 & 9.8 & 2757.3 \\
\hline 1228.5 & 5.4 & 470.8 & 1038.9 & 19.9 & 509.3 \\
\hline 1464.8 & 5.7 & 170.5 & 890.5 & 27.6 & 1301.6 \\
\hline 1316.9 & 5.5 & 251.2 & 1387.5 & 24.0 & 38.2 \\
\hline 1320.2 & 5.1 & 371.7 & 1026.5 & 19.1 & 513.3 \\
\hline 1362.9 & 5.5 & 254.1 & 1169.7 & 25.8 & 116.6 \\
\hline 1137.3 & 11.3 & 429.0 & 1103.2 & 16.5 & 310.6 \\
\hline 1212.2 & 11.5 & 242.6 & 1299.2 & 23.7 & 51.8 \\
\hline 960.6 & 10.3 & 952.4 & 1177.1 & 20.9 & 140.9 \\
\hline 1393.4 & 10.2 & 98.5 & 1238.5 & 22.6 & 96.0 \\
\hline 973.9 & 9.1 & 1011.4 & 956.9 & 22.1 & 756.9 \\
\hline \multicolumn{6}{|c|}{ Kerosene $/ \mathrm{O}_{2} / \mathrm{Ar}, \phi=1.5$, Kerosene $=1.8 \%, \mathrm{O}_{2}=19.88 \%, \mathrm{Ar}=78.32 \%$} \\
\hline 1172 & 5.6 & 624.5 & 918.2 & 5.6 & 1464.2 \\
\hline 1082.5 & 5.5 & 722.3 & 1185.3 & 10.2 & 274.7 \\
\hline 971.2 & 7.6 & 1312.4 & 1277.3 & 10.8 & 247.9 \\
\hline 885.7 & 5.1 & 1585.2 & 1110.3 & 11.6 & 427.4 \\
\hline 1190.9 & 5.2 & 561.6 & 965.6 & 9.5 & 1230.3 \\
\hline 1282.7 & 5.4 & 380.0 & 823.8 & 10.9 & 2869.9 \\
\hline 1040.3 & 5.9 & 959.8 & 910.8 & 11.2 & 1543.9 \\
\hline 967.3 & 6.4 & 1331.0 & 1032.4 & 10.9 & 928.9 \\
\hline
\end{tabular}

of ignition delay times with different equivalence ratios would intersect at a lower temperature beyond the present experimental range. This tendency is unlike the ignition behavior exhibited by single-component hydrocarbon fuels, in which the sensitivity of ignition delay times to the stoichiometry appears to be essentially constant [18].

A least square analysis was performed to correlate the measured ignition delay times of China No. 3 aviation kerosene with different variables. Over a wider temperature range of $820-1500 \mathrm{~K}$, the correlations were obtained with an $R^{2}$ value of 0.92 in the following form:

$$
\begin{gathered}
\tau=3.20 \times 10^{-11}[\text { Kerosene }]^{0.22}\left[\mathrm{O}_{2}\right]^{-1.09} \exp (69941 / R T), \\
\tau=4.72 \times 10^{-7} P^{-0.88} \phi^{0.23} \exp (62092 / R T)
\end{gathered}
$$

where $\tau$ is the ignition delay time in seconds, $\phi$ is the stoichiometric ratio, [Kerosene] and $\left[\mathrm{O}_{2}\right]$ are concentrations in $\mathrm{mol} / \mathrm{cm}^{3}, P$ is pressure in atm, and the activation energy is in $\mathrm{J} / \mathrm{mol}$. The kerosene ignition delay times and the correlation are plotted in Figure 11.

In eq. (1), the ignition delay times are expressed in terms of the temperature and the kerosene and oxygen concentra- 


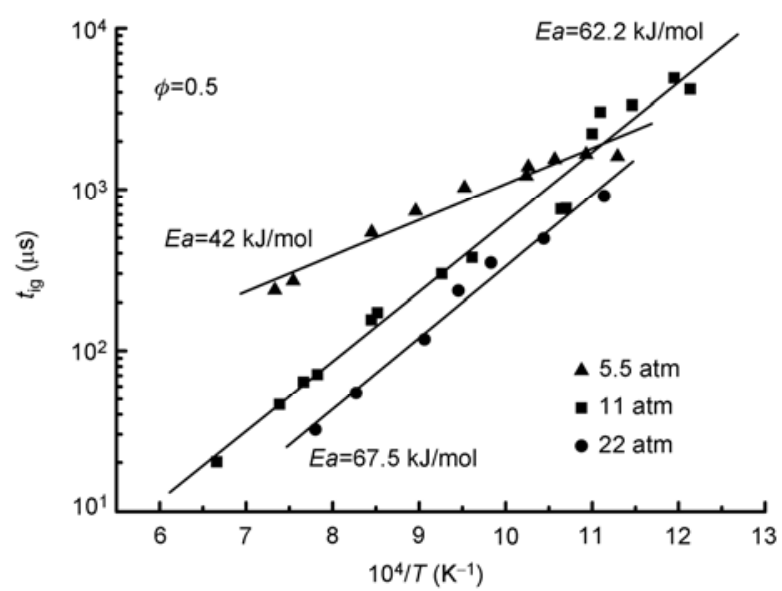

Figure 5 Effect of pressure on the ignition delay of kerosene at $\phi=0.5$.

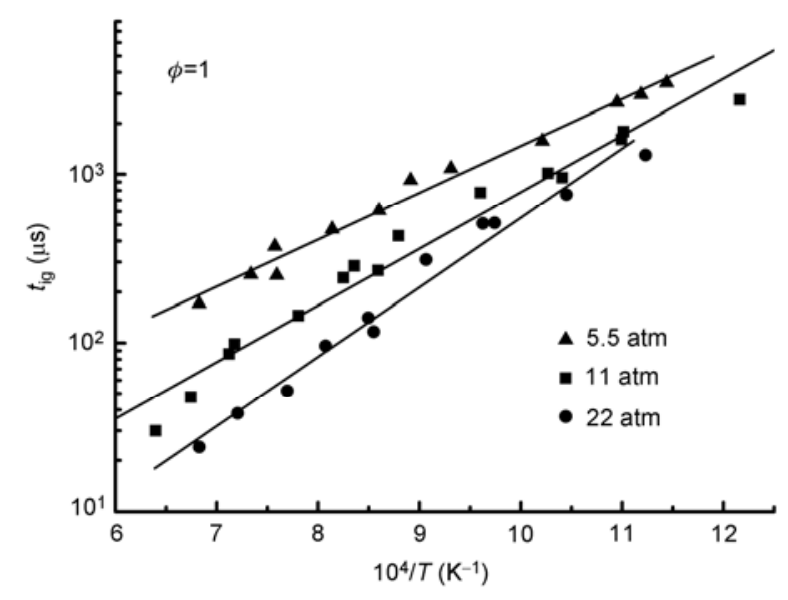

Figure 6 Effect of pressure on the ignition delay of kerosene at $\phi=1.0$.

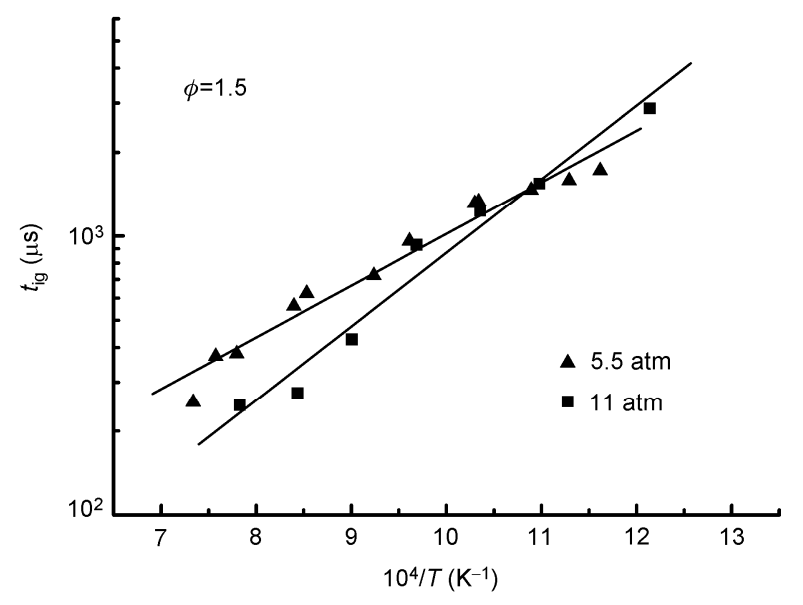

Figure 7 Effect of pressure on the ignition delay of kerosene at $\phi=1.5$.

tions, whereas in eq. (2) the correlation of the ignition delay times with more practical parameters, pressure and stoichiometric ratio, is explicitly expressed.

Eqs. (1) and (2) show the strong power law dependence

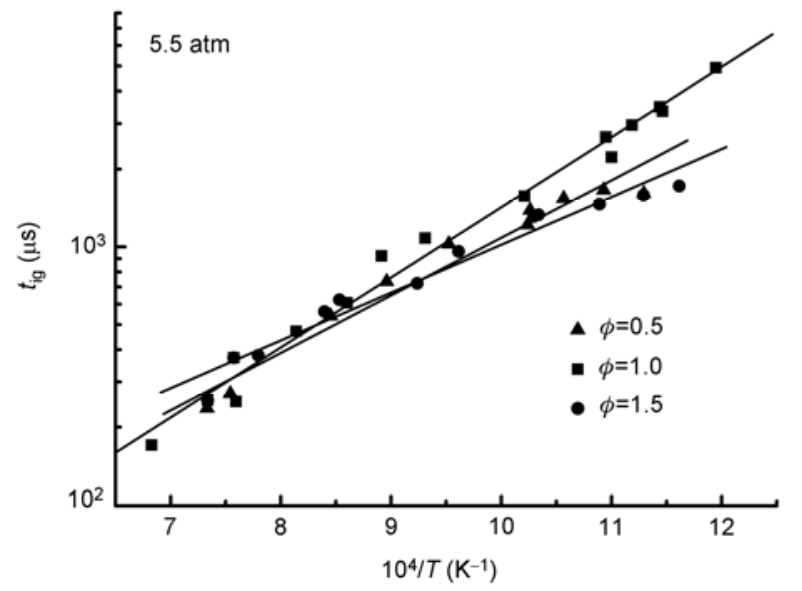

Figure 8 Effect of stoichiometry on the ignition delay of kerosene at 5.5 atm.

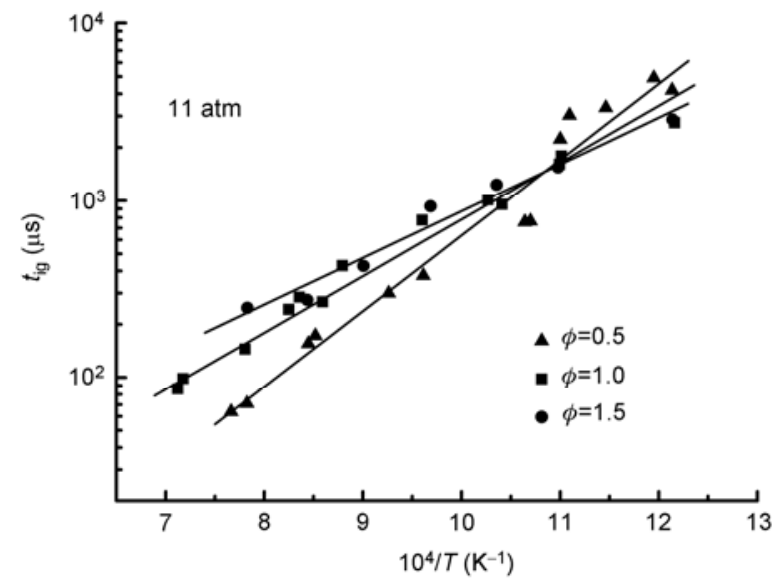

Figure 9 Effect of stoichiometry on the ignition delay of kerosene at 11 atm.

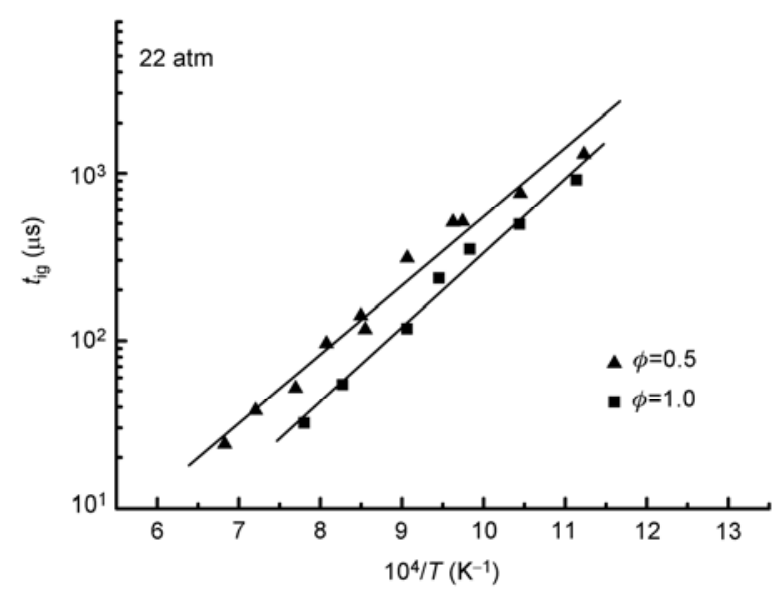

Figure 10 Effect of stoichiometry on the ignition delay of kerosene at 22 atm.

of kerosene ignition delay times on both oxygen concentration and ignition pressure, whereas the dependence of igni- 


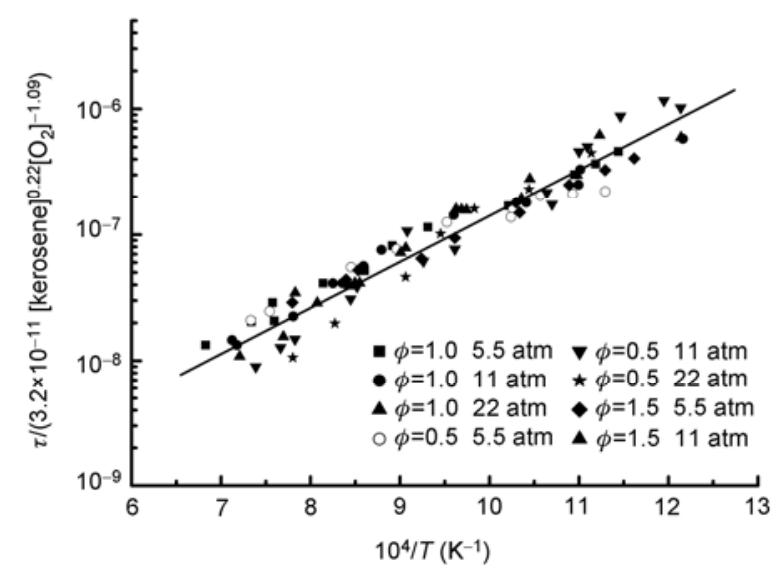

Figure 11 Ignition delay times of China No. 3 aviation kerosene. Symbols are the present experimental data, line is the correlation result.

tion delay times on the kerosene concentration and the stoichiometry is relatively weak, and their power dependencies are relatively small positive values. The oxygen concentration dependence for the ignition delay of kerosene is a relatively large negative value of -1.09 , which is in good agreement with the reported average value of -1.1 for single component hydrocarbon fuels in the literatures [18], suggesting that oxygen also plays an important role in determining ignition delay times of kerosene. To explain the observed behavior and further validate the correlations presented in this study, it is recommended that further work involve comparisons of the simulated ignition delay times with a chemical kinetic model to those found experimentally.

To compare the present measured ignition delay times of China No. 3 aviation kerosene with the other shock tube studies for Jet-A ignition under similar conditions, the present stoichiometric ignition delay time data are shown in Figure 12 along with the respective data from Dean et al. [6] and Vasu et al. [7]. For comparison at the same pressure, the ignition delay times obtained by Dean et al. and Vasu et al. have been normalized to 22 atm assuming $t_{i g} \sim P^{-0.88}$ according to eq. (2). Figure 12 shows a relatively good agreement between both earlier studies for gaseous Jet-A by Dean et al. and Vasu et al., furthermore their measurements give the ignition delay times consistent to the present measured data for China No. 3 aviation kerosene at high temperatures, but the data deviates away slightly at lower temperatures (approximately below $1000 \mathrm{~K}$ ). Since the compositions between Jet-A and China No. 3 aviation kerosene are apparently different, this discrepancy in ignition delay times could be attributed to the fuel type studied. The volumetric composition of Jet-A contains $27.1 \%$ of paraffins and isoparaffins, $21.5 \%$ of aromatics, $2.9 \%$ of naphthenes, and $1.1 \%$ of olefins [6]. Compared to the content of $7 \%$ aromatics in China No. 3 aviation kerosene, the more aromatic compounds in Jet-A should be responsible for the characteristics of longer ignition delay times at lower tempera-

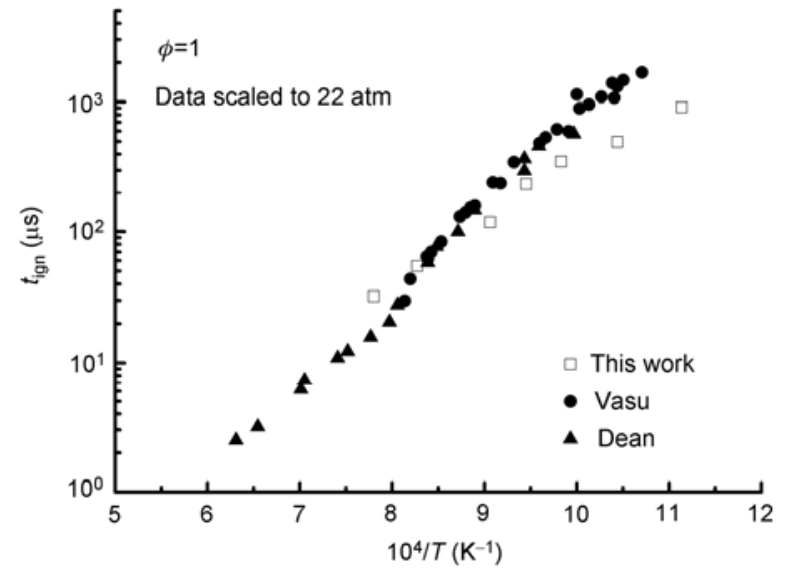

Figure 12 Comparison of stoichiometric ignition delay times of China No. 3 aviation kerosene with other studies for Jet-A.

tures, where the fuel pyrolysis plays an important role. This comparison suggests that the combustion performance of practical engines could be affected by variations in fuel type, and more detailed studies are needed to understand these differences.

\section{Conclusions}

The ignition delay times of China No. 3 aviation kerosene were measured in a heated shock tube over a temperature range of $820-1500 \mathrm{~K}$, at pressures of 5.5, 11 and 22 atm, and equivalence ratios of $0.5,1.0$ and 1.5. The kerosene adsorption on shock tube wall was taken into account, and the kerosene concentration was determined by directly measuring the vapor pressure with a high-precision vacuum gauge. These measured ignition delay times are correlated with temperature, pressure, stoichiometry, and concentrations of kerosene and oxygen. The results show that the ignition delay times of China No. 3 aviation kerosene exhibit relatively strong power dependencies on oxygen concentration and pressure, whereas the fuel concentration and the stoichiometry have relatively weak power dependencies.

The comparison between Jet-A and China No. 3 aviation kerosene shows good agreement between the measured ignition delay times for both fuels at high temperatures. Only at lower temperatures (approximately below $1000 \mathrm{~K}$ ) the ignition delay times of China No. 3 aviation kerosene appear to be apparently shorter than those of Jet-A. The present measurements will provide the ignition behavior of China No. 3 aviation kerosene at high pressures and air-like $\mathrm{O}_{2}$ concentrations.

This work was supported by the National Natural Science Foundation of China (Grant No. 90916017).

1 Tishkoff J M, Drummond J P, Edwards T, et al. Future direction of 
supersonic combustion research: Air Force/NASA workshop on supersonic combustion. In: 35th Aerospace Sciences Meeting and Exhibit. Reno, Nevada. AIAA Paper, 1997, AIAA-1997-1017

2 Held T J, Marchese A J, Dryer F L. A semi-empirical reaction mechanism for n-heptane oxidation and pyrolysis. Combust Sci Technol, 1997, 123(1-6): 107-146

3 Li S C, Varatharajan B, Williams F A. Chemistry of JP-10 ignition. AIAA J, 2001, 39(12): 2351-2356

4 Davidson D F, Hanson R K. Interpreting shock tube ignition data. Int J Chem Kin, 2004, 36(9): 510-523

5 Mullins B P. Studies on the spontaneous ignition of fuels injected into a hot air-stream. Part 2: The effect of physical factors upon the ignition delay of kerosene-air mixtures. Fuel, 1953, 32(2): 234-252

6 Dean A J, Penyazkov O G, Sevruk K L, et al. Autoignition of surrogate fuels at elevated temperatures and pressures. Proc Combust Inst, 2007, 31: 2481-2488

7 Vasu S S, Davidson D F, Hanson R K. Jet fuel ignition delay times: Shock tube experiments over wide conditions and surrogate model predictions. Combust Flame, 2008, 152(1-2): 125-143

8 Steil U, Braun-Unkhoff M, Aigner M, et al. An experimental and modeling study on the autoignition of kerosene and surrogate fuel mixture. In: 46th AIAA Aerospace Sciences Meeting, Reno, Nevada. AIAA Paper, 2008, AIAA-2008-973

9 Kumar K, Sung C J. An experimental study of the autoignition characteristics of conventional jet fuel/oxidizer mixtures: Jet-A and JP-8.
Combust Flame, 2010, 157(4): 676-685

10 Wang S, Fan B C, He Y Z, et al. Shock tube study of kerosene ignition delay. Shock Waves, Part IX, 2009, 16(1): 775-780

11 Liao Q, Xu S L. The ignition delay measurement of atomized kerosene air mixture in an aerosol shock tube (in Chinese). J Exp Fluid Mech, 2009, 23(3): 70-74

12 Petersen E L, Röhrig M, Davidson D F, et al. High-pressure methane oxidation behind reflected shock waves. Proc Combust Inst, 1996, 26(1): 799-806

13 Petersen E L, Davidson D F, Hanson R K. Ignition delay times of ram accelerator $\mathrm{CH}_{4} / \mathrm{O}_{2}$ /diluent Mixtures. Prop Power, 1999, 15(1): 82-91

14 Petersen E L, Davidson D F, Hanson R K. Kinetics modeling of shock-induced ignition in low-dilution $\mathrm{CH}_{4} / \mathrm{O}_{2}$ mixtures at high pressures and intermediate temperatures. Combust Flame, 1999, 117(1-2): 272-290

15 Fan X J, Yu G. Analysis of thermophysical properties of Daqing RP-3 aviation kerosene (in Chinese). J Prop Technol, 2006, 27(2): 188-192

16 Gaseq Chemical Equilibrium Program. Computerized Educational Systems. Version 0.79. New York: Columbia University, 2005

17 Tang W T, Brezinsky K. Chemical kinetics simulations behind reflected shock waves. Int J Chem Kinet, 2006, 38(2): 75-97

18 Horning D C. A Study of the High Temperature Auto-Ignition and Thermal Decomposition of Hydrocarbons. Dissertation for Doctoral Degree. Stanford: Stanford University, 2001 